\title{
Your body, my body, our coupling moves our bodies
}

\author{
Guillaume Dumas ${ }^{1,2,3}$, Julien Laroche ${ }^{4}$ and Alexandre Lehmann ${ }^{5,6,7}$ \\ 1 Institut Pasteur, Human Genetics and Cognitive Functions Unit, Paris, France \\ ${ }^{2}$ CNRS UMR3571 Genes, Synapses and Cognition, Institut Pasteur, Paris, France \\ ${ }^{3}$ Human Genetics and Cognitive Functions, University Paris Diderot, Sorbonne Paris Cité, Paris, France \\ ${ }^{4}$ Akoustic Arts, Paris, France \\ ${ }^{5}$ Department of Otolaryngology - Head and Neck Surgery, Faculty of Medicine, McGill University, Montreal, QC, Canada \\ ${ }^{6}$ Centre for Research on Brain, Language and Music, Montreal, QC, Canada \\ 7 International Laboratory for Brain, Music and Sound Research, Montreal, OC, Canada \\ ${ }^{*}$ Correspondence: guillaume.dumas@pasteur.fr
}

Edited by:

Jessica Phillips-Silver, Georgetown University Medical Center, USA

Reviewed by:

Gregory Bryant, University of California, Los Angeles, USA

Keywords: coupling, coordination, interpersonal, dynamical systems, human interaction

Sensitivity to temporal contingencies appears early in life and plays a key role in the ontogeny of socio-cognitive abilities in humans (Nadel et al., 1999; Gratier and Apter-Danon, 2009). The tendency for rhythmic coordination, sometimes referred to as "entrainment," requires sensory-motor coupling (Phillips-Silver et al., 2010). In most of the fields of cognitive science, action-perception and agent-world coupling views are replacing the classical stimulus-response dichotomy (Marsh et al., 2009; Silberstein and Chemero, 2012; Schilbach et al., 2013; Novembre and Keller, 2014). Such conceptual frameworks are well suited to study coordination phenomena as they emphasize the dynamical nature of cognition (Varela et al., 1993; Kelso, 1995; Buzsáki and Draguhn, 2004; Lehmann and Schönwiesner, 2014). Moreover, they leave room for the balance of autonomy, a central feature of complex biological systems, and interactive coupling, through which such systems relate to-and make sense of-their environment (Di Paolo, 2005; Barandiaran et al., 2009; Buhrmann et al., 2013). A naturalistic study of autonomy and coupling requires both embracing ecological situations and considering firstperson perspective. Furthermore, many social coordination phenomena cannot be observed in the laboratory without the interaction of at least two subjects. We propose to consider linking first- and third-person measures, and even relate them across multiple interacting individuals. We will discuss how these concepts are intertwined in coordination phenomena, and outline existing methods to address those issues.

\section{COUPLING AND AUTONOMY, THE TWO FACES OF COORDINATION}

Coordination is related to two complementary aspects: autonomy and interactive coupling (Clayton et al., 2004). Autonomy refers to the intrinsic laws of organization of a living system (Varela, 1979). In turn, such laws define the environment to which a living system can couple. Autonomy thus provides a system with a dynamical background in the context of which sensory perturbations occur; it provides a perspective that shapes the lived world. In turn, as a result of their modulation, internal dynamics carry the imprint of the system's own environment. In other words, internal dynamics depend on agent $\sim$ world relational dynamics (i.e., they depend on the way the relation between agent and world evolves). In short, complex systems and their environment co-determine each other. Patterns of coordination thus emerge dynamically from agent $\sim$ world coupling and are therefore both autonomous and relational. By emergence, we mean that despite the fact that coordination is a by-product of intra-individual processes (Ross and Balasubramaniam, 2014), it is not reducible to them. In this opinion, we emphasize the inter-individual dimension of coordination, especially in the case of the human specific activities of music and dance [numerous ways of interacting have been studied in animals and humans (Strogatz, 2003), ranging from flock behavior (Okubo, 1986) to language (Dale et al., 2013; Manson et al., 2013)].

Rhythmic coordination of movements emerges from the dynamics of interaction between multiple component processes (Kelso, 1995; see also Van Orden et al., 2003); those interactions bring forth a dynamical landscape that preorients behavior and that can be modulated by intention (Kelso, 2002). For instance, rhythmic coordination of two limbs is driven by the dynamics of their relation, rather than by their sole intrinsic properties (Kelso, 1984). Coordination of one limb to an external pacer is governed by their relational dynamics as well (Kelso, 1981). Such dynamical interactions lead to coordination of activity across multiple scales of brain and behavior (Ihlen and Vereijken, 2010; Kelso et al., 2013). Human subjects can embody both plurifrequential rhythms (Toiviainen et al., 2010) and the complexity of their fluctuations (Rankin et al., 2009; Marmelat et al., 2014). Thanks to the intrinsic complexity that underlies behavioral coordination, coupling allows coordination with the environment across scales (Laroche et al., 2014). If relational dynamics play a role in rhythmic coordination they may also play a key role in social interaction. Indeed, interacting with others is organized rhythmically and at multiple timescales since infancy (Gratier and Apter-Danon, 2009). The development 
of our capacity to coordinate rhythmically might lie in the dynamics of social interactions, rather than in purely intraindividual processes (Dumas, 2011): while we obviously need intra-individual capacities (e.g., vision) to handle social interaction, the development of our coordination capacities is shaped by those interactions as well (De Jaegher et al., 2010; Dumas et al., 2014b; Froese et al., 2014b)

Two-body approaches-at least two participants interacting in real-timedemonstrate that interactive contexts bring forth different qualities of coordination, in comparison with perceptive contexts in which participants' behaviors do not have any impact on their environment. Indeed, mutual interaction allows for more accurate/stable coordination than unilateral situations where only one partner is responsive to the other (Cummins, 2009; Konvalinka et al., 2010; Noy et al., 2011). Dynamics that are properly collective thus arise in mutual interaction, and they can attract and coordinate individual behaviors (De Jaegher and Di Paolo, 2007; Auvray et al., 2009; Lenay and Stewart, 2012; Laroche and Kaddouch, 2014). Such dynamics are therefore irreducible to purely intraindividual processes. Interacting subjects can yet rely on those relational dynamics; they can jointly regulate them. Overall, neither the dynamics of the interaction process nor their co-regulation can be observed when subjects are isolated from each other. It is thus important to study the dynamical properties of the interaction process itself in order to understand how we co-regulate them. More individuallycentered processes of coordination might derive from recurrent social interactions. Recent methodological and technological advances make this change of paradigm possible.

\section{DECIPHERING FACTORS ENABLING COORDINATION THROUGH AN ECOLOGICAL AND DYNAMICAL APPROACH}

Recent technological improvements made the continuous tracking of complex movements possible. For instance, whole-body motion capture through multi-camera settings showed that subjects can coordinate their movements simultaneously to multiple timescales of musical events
(Toiviainen et al., 2010). Low-cost motion capture devices such as wireless accelerometers from video-game devices have been used to ecologically investigate interpersonal coordination between listeners dancing to music (De Bruyn et al., 2009). Recent analytical tools can deal with non-linear dynamics of movements and interpersonal coordination across multiple timescales [e.g., windowed-cross correlation (Boker et al., 2002); crosswavelet transform (Issartel et al., 2007); frame-differencing methods (Paxton and Dale, 2013); cross-recurrence quantification analysis (Coco and Dale, 2014; Demos et al., 2014); detrended crosscorrelation analysis (Hennig, 2014); multifractal detrended fluctuation analysis (Bedia et al., 2014)]. Such behavioral measures can discriminate between roles (i.e., leader/follower, Sacheli et al., 2013), individual strategies of regulation of coupling (Fairhurst et al., 2014), types of personality (Schmidt et al., 1994) or can identify signatures of social disorders (Varlet et al., 2014). With tools grasping the complexity of movements, more ecological experiments are within reach.

Several innovations in brain-imaging methods can be readily applied to the study of rhythmic coordination in music and dance contexts. Through a careful design of control conditions, the use of ecological musical stimuli is possible in fMRI (Blood and Zatorre, 2001) as well as in EEG with the Steady-States Evoked Potential (SS-EP) technique. Traditional event-related potential approaches require numerous stimuli repetitions; hence stimuli durations are usually kept to a minimum. With the SS-EP technique, a continuous stimulus such as music that has a periodic structure (or is frequencytagged) can be presented and requires very few repetitions. It has been used successfully to demonstrate neural oscillations underlying listening and tapping to synthetic beats (Nozaradan et al., 2011, 2012, 2013) and could be extended to study ecological musical beats. Adequately studying natural cognition may require the integration of multiple modality and sensing techniques, while participants move freely (Makeig et al., 2009; Gramann et al., 2014). The recent years have seen the development of wearable devices for electrophysiological (Codrons et al., 2014), as well as EEG recordings (Debener et al., 2012; De Vos et al., 2014), allowing to experiment in contexts more ecological than the laboratory (e.g., a concert venue). As smartphones get powerful enough to process brain signals in real-time, conducting in-field or at-home EEG protocols is becoming feasible (Stopczynski et al., 2014). Because those systems are low-cost and yet can provide research-grade quality signals (Badcock et al., 2013), they can easily scale up to record multiple participants.

Over the last decade, social neuroscience took an interactive turn. Two-body and second-person neuroscience have especially been supporting the use of ecological paradigms for understanding the neural underpinning of social interaction (Schilbach et al., 2013). This ongoing interactive turn relies on the development of new methods. Hyperscanning, for instance, allows recording the brain activity of multiple individuals engaged in an interaction. This approach already demonstrated differential effects of social context (e.g., induced/spontaneous, see Dumas et al., 2012a) and role (e.g., leader/follower, see Dumas et al., 2012a; Sänger et al., 2013; Konvalinka et al., 2014) during interpersonal coordination. Music is an ideal ecological context for the study of coordination and has been used in the burgeoning field of social interaction neuroscience. The work of Lindenberger and colleagues has for instance revealed the inter-individual brain dynamics of joint improvisation (Müller et al., 2013) and how the global system should be described through both intra- and interindividual processes (Sänger et al., 2012). An open question is how much does the observed inter-brain relationships rely on shared biological structure (Dumas et al., 2012b), task and environment (Burgess, 2013), or even cultural background (Vogeley and Roepstorff, 2009; Kitayama and Park, 2010). For instance, heart rate coordination can be induced by a common task (e.g., singing the same song in Vickhoff et al., 2013) or socially modulated coupling (Konvalinka et al., 2011). Neurocomputational modeling has already helped to measure the potential contribution of similarity at both anatomical and dynamical levels to our propensity to coordinate with others (Dumas et al., 2012b). Such empirically grounded 
models can moreover be combined with experiments through human-machine interaction (Dumas et al., 2014a). This is especially interesting for operationalizing real time and reciprocal social interactions while keeping a rigorous experimental control (e.g., parametrically manipulate coupling).

While at the objective level, many approaches have been proposed to relate intra- and inter-individual dynamics (Hasson et al., 2012; Konvalinka and Roepstorff, 2012; Dumas et al., 2014b), the link between the third (objective) and first person (subjective) accounts remains unclear. How can interaction help escaping this dichotomy? We argue that closing this gap requires a joint study of intrinsic and relational dynamics. Introspection in experimental psychology has been heavily criticized in the past decades, but more rigorous approaches are now being designed to study subjective experience while overcoming previous limitations (Bockelman et al., 2013; Petitmengin and Lachaux, 2013). Recent work has managed to question the lived experience of the intersubjective dimension of coordination (Froese et al., 2014a). The neurophenomenological approach demonstrates the feasibility of integrating first-person data with objective measures from cognitive neuroscience (Lutz et al., 2002; Fox et al., 2013). Despite those promising advances, the joint study of first and third person perspectives remains underrepresented in the literature. Music can provide a nice entry point to bridge the gap between the intimate subjective experience and objective brain $\sim$ body processes (Flaig and Large, 2014). For instance, listeners experience modulates both emotional and neural responses (Chapin et al., 2010) and expert dancers display greater coherence between their subjective and physiological aspects of emotion (Sze et al., 2010).

\section{CONCLUSION}

We have seen how rhythmic and social coordination rely on both intrinsic and relational dynamics, namely autonomy and coupling. The complementarity of those two aspects of coordination has been empirically demonstrated, but many challenges remain. Two issues appear at reach with available methodologies: (1) quantifying how interactions with the environment and others have a causal role at the intra-individual level and non-additive consequences at the interindividual level, and (2) deciphering the different factors of coupling across neural, behavioral and cultural scales. A last challenge is to embrace the ongoing change of paradigm that shall bridge the gap between the lived and the observed experience of social coordination in ecological contexts. Taken together, integrating first-, secondand third-person perspectives is a required move to accurately study natural human coordination phenomena.

\section{ACKNOWLEDGMENTS}

Guillaume Dumas thanks Craig Nordham and Karl Lerud for early discussions about this topic. The authors thank Michael Zager and Alvin Fields for inspiring the title of this article with their song "Let's all chant" (1977).

\section{REFERENCES}

Auvray, M., Lenay, C., and Stewart, J. (2009). Perceptual interactions in a minimalist virtual environment. New Ideas Psychol. 27, 32-47. doi: 10.1016/j.newideapsych.2007.12.002

Badcock, N. A., Mousikou, P., Mahajan, Y., de Lissa, P., Thie, J., and McArthur, G. (2013). Validation of the Emotiv EPOC $\left({ }^{\circledR}\right)$ EEG gaming system for measuring research quality auditory ERPs. PeerJ. 1:e38. doi: 10.7717/peerj.38

Barandiaran, X. E., Di Paolo, E., and Rohde, M. (2009). Defining agency: individuality, normativity, asymmetry, and spatio-temporality in action. Adapt. Behav. 17, 367-386. doi: 10.1177/1059712309343819

Bedia, M. G., Aguilera, M., Gómez, T., Larrode, D. G., and Seron, F. (2014). Quantifying long-range correlations and $1 / \mathrm{f}$ patterns in a minimal experiment of social interaction. Front. Psychol. 5:1281. doi: 10.3389/fpsyg.2014.01281

Blood, A. J., and Zatorre, R. J. (2001). Intensely pleasurable responses to music correlate with activity in brain regions implicated in reward and emotion. Proc. Natl. Acad. Sci. U.S.A. 98, 11818-11823. doi: 10.1073/pnas. 191355898

Bockelman, P., Reinerman-Jones, L., and Gallagher, S. (2013). Methodological lessons in neurophenomenology: review of a baseline study and recommendations for research approaches. Front. Hum. Neurosci. 7:608. doi: 10.3389/fnhum.2013. 00608

Boker, S. M., Rotondo, J. L., Xu, M., and King, K. (2002). Windowed cross-correlation and peak picking for the analysis of variability in the association between behavioral time series. Psychol. Methods 7:338. doi: 10.1037/1082-989X.7.3.338

Buhrmann, T., Di Paolo, E. A., and Barandiaran, X. (2013). A dynamical systems account of sensorimotor contingencies. Front. Psychol. 4:285. doi: 10.3389/fpsyg.2013.00285
Burgess, A. P. (2013). On the interpretation of synchronization in EEG hyperscanning studies: a cautionary note. Front. Hum. Neurosci. 7:881. doi: 10.3389/fnhum.2013.00881

Buzsáki, G., and Draguhn, A. (2004). Neuronal oscillations in cortical networks. Science 304, 1926-1929. doi: 10.1126/science. 1099745

Chapin, H., Jantzen, K., Kelso, J. S., Steinberg, F., and Large, E. (2010). Dynamic emotional and neural responses to music depend on performance expression and listener experience. PLoS ONE 5:e13812. doi: 10.1371/journal.pone.0013812

Clayton, M., Sager, R., and Will, U. (2004). In time with the music: the concept of entrainment and its significance for ethnomusicology. ESEM Counterpoint 1, 1-82. Available online at: http://oro.open.ac.uk/2661/?LKCAMPAIGN = it00 1_res\&MEDIA=it001_c03

Coco, M. I., and Dale, R. (2014). Cross-recurrence quantification analysis of categorical and continuous time series: an R package. Front. Psychol. 5:510. doi: 10.3389/fpsyg.2014.00510

Codrons, E., Bernardi, N. F., Vandoni, M., and Bernardi, L. (2014). Spontaneous group synchronization of movements and respiratory rhythms. PLoS ONE 9:e107538. doi: 10.1371/journal.pone. 0107538

Cummins, F. (2009). Rhythm as entrainment: the case of synchronous speech. J. Phon. 37, 16-28. doi: 10.1016/j.wocn.2008.08.003

Dale, R., Fusaroli, R., Duran, N., and Richardson, D. C. (2013). The self-organization of human interaction. Psychol. Learn. Motiv. 59, 43-95. doi: 10.1016/B978-0-12-407187-2.00002-2

Debener, S., Minow, F., Emkes, R., Gandras, K., and de Vos, M. (2012). How about taking a low-cost, small, and wireless EEG for a walk? Psychophysiology 49, 1617-1621. doi: 10.1111/j. 1469-8986.2012.01471.x

De Bruyn, L., Leman, M., Moelants, D., and Demey, M. (2009). "Does social interaction activate music listeners?," in Computer Music Modeling and Retrieval. Genesis of Meaning in Sound and Music, eds Y. Sølvi, K.-M. Richard, and J. Kristoffer (Berlin; Heidelberg: Springer), 93-106.

De Jaegher, H., and Di Paolo, E. (2007). Participatory sense-making. Phenomenol. Cogn. Sci. 6, 485-507. doi: 10.1007/s11097-007-9076-9

De Jaegher, H., Di Paolo, E., and Gallagher, S. (2010). Can social interaction constitute social cognition? Trends. Cogn. Sci. 14, 441-447. doi: 10.1016/j.tics.2010.06.009

Demos, A. P., Chaffin, R., and Kant, V. (2014). Toward a dynamical theory of body movement in musical performance. Front. Psychol. 5:477. doi: 10.3389/fpsyg.2014.00477

De Vos, M., Gandras, K., and Debener, S. (2014). Towards a truly mobile auditory braincomputer interface: exploring the P300 to take away. Int. J. Psychophysiol. 91, 46-53. doi: 10.1016/j.ijpsycho.2013.08.010

Di Paolo, E. A. (2005). Autopoiesis, adaptivity, teleology, agency. Phenomenol. Cogn. Sci. 4, 429-452. doi: 10.1007/s11097-005-9002-y

Dumas, G. (2011). Towards a two-body neuroscience. Commun. Integr. Biol. 4, 349. doi: 10.4161/cib.4.3.15110

Dumas, G., Chavez, M., Nadel, J., and Martinerie, J. (2012b). Anatomical connectivity influences both 
intra-and inter-brain synchronizations. PLOS ONE 7:e36414. doi: 10.1371/journal.pone.0036414

Dumas, G., de Guzman, G. C., Tognoli, E., and Kelso, J. A. S. (2014a). The human dynamic clamp as a paradigm for social interaction. Proc. Natl. Acad. Sci. U.S.A. 111, E3726-E3734. doi: 10.1073/pnas.1407486111

Dumas, G., Kelso, J. A. S., and Nadel, J. (2014b). Tackling the social cognition paradox through multi-scale approaches. Front. Psychol. 5:882. doi: 10.3389/fpsyg.2014.00882

Dumas, G., Martinerie, J., Soussignan, R., and Nadel, J. (2012a). Does the brain know who is at the origin of what in an imitative interaction? Front. Hum. Neurosci. 6:128. doi: 10.3389/fnhum.2012.00128

Fairhurst, M. T., Janata, P., and Keller, P. E. (2014). Leading the follower: an fMRI investigation of dynamic cooperativity and leader-follower strategies in synchronization with an adaptive virtual partner. Neuroimage 84, 688-697. doi: 10.1016/j.neuroimage.2013.09.027

Flaig, N. K., and Large, E. W. (2014). Dynamic musical communication of core affect. Front. Psychol. 5:72. doi: 10.3389/fpsyg.2014.00072

Fox, K. C. R., Nijeboer, S., Solomonova, E., Domhoff, G. W., and Christoff, K. (2013). Dreaming as mind wandering: evidence from functional neuroimaging and first-person content reports. Front. Hum. Neurosci. 7:412. doi: 10.3389/fnhum.2013.00412

Froese, T., Iizuka, H., and Ikegami, T. (2014a). Embodied social interaction constitutes social cognition in pairs of humans: a minimalist virtual reality experiment. Sci. Reports 4:3672. doi: 10.1038/srep03672

Froese, T., Iizuka, H., and Ikegami, T. (2014b). Using minimal human-computer interfaces for studying the interactive development of social awareness. Front. Psychol. 5:1061. doi: 10.3389/fpsyg. 2014.01061

Gramann, K., Jung, T.-P., Ferris, D. P., Lin, C.T., and Makeig, S. (2014). Toward a new cognitive neuroscience: modeling natural brain dynamics. Front. Hum. Neurosci. 8:444. doi: 10.3389/fnhum.2014.00444

Gratier, M., and Apter-Danon, G. (2009). "The improvised musicality of belonging: Repetition and variation in mother-infant vocal interaction," in Communicative musicality: Exploring the basis of human companionship, eds S. Malloch and C. Trevarthen (Oxford: Oxford University Press), 301-327.

Hasson, U., Ghazanfar, A. A., Galantucci, B., Garrod, S., and Keysers, C. (2012). Brain-to-brain coupling: a mechanism for creating and sharing a social world. Trends Cogn. Sci. 16, 114-121. doi: 10.1016/j.tics.2011.12.007

Hennig, H. (2014). Synchronization in human musical rhythms and mutually interacting complex systems. Proc. Natl. Acad. Sci. U.S.A. 111, 12974-12979. doi: 10.1073/pnas.1324142111

Ihlen, E. A., and Vereijken, B. (2010). Interactiondominant dynamics in human cognition: beyond 1/f $\alpha$ fluctuation. J. Exp. Psychol. Gen. 139, 436. doi: $10.1037 / \mathrm{a} 0019098$

Issartel, J., Marin, L., and Cadopi, M. (2007). Unintended interpersonal co-ordination: "can we march to the beat of our own drum?" Neurosci. Lett. 411, 174-179. doi: 10.1016/j.neulet.2006. 09.086
Kelso, J. A. S. (1981). On the oscillatory basis of movement. Bull. Psychon. Soc. 18, 63-63.

Kelso, J. A. S. (1984). Phase transitions and critical behavior in human bimanual coordination. Am. J. Physiol. 246(6 pt 2), R1000-R1004.

Kelso, J. A. S. (1995). Dynamic Patterns: The SelfOrganization of Brain and Behavior. Cambridge, MA: A Bradford Book.

Kelso, J. A. S. (2002). The complementary nature of coordination dynamics: self-organization and agency. Nonlinear Phenomena Complex Systems 5, 364-371.

Kelso, J. A., Dumas, G., and Tognoli, E. (2013). Outline of a general theory of behavior and brain coordination. Neural Netw. 37, 120-131. doi: 10.1016/j.neunet.2012.09.003

Kitayama, S., and Park, J. (2010). Cultural neuroscience of the self: understanding the social grounding of the brain. Soc. Cogn. Affect. Neurosci. 5, 111-129. doi: 10.1093/scan/ nsq052

Konvalinka, I., Bauer, M., Stahlhut, C., Hansen, L. K., Roepstorff, A., and Frith, C. D. (2014). Frontal alpha oscillations distinguish leaders from followers: multivariate decoding of mutually interacting brains. NeuroImage 94, 79-88. doi: 10.1016/j. neuroimage.2014.03.003

Konvalinka, I., and Roepstorff, A. (2012). The twobrain approach: how can mutually interacting brains teach us something about social interaction? Front. Hum. Neurosci. 6:215. doi: 10.3389/fnhum. 2012.00215

Konvalinka, I., Vuust, P., Roepstorff, A., and Frith, C. D. (2010). Follow you, follow me: continuous mutual prediction and adaptation in joint tapping. Q. J. Exp. Psychol. A. 63, 2220-2230. doi: 10.1080/ 17470218.2010.497843

Konvalinka, I., Xygalatas, D., Bulbulia, J., Schjødt, U., Jegindø, E. M., Wallot, S., et al. (2011). Synchronized arousal between performers and related spectators in a firewalking ritual. Proc. Natl. Acad. Sci. U.S.A. 108, 8514-8519. doi: 10.1073/pnas.1016 955108

Laroche, J., Berardi, A., and Brangier, E. (2014). Embodiment of intersubjective time: relational dynamics as attractors in the temporal coordination of interpersonal behaviors and experiences. Front. Psychol. 5:1180. doi: 10.3389/fpsyg.2014.01180

Laroche, J., and Kaddouch, I. (2014). Enacting teaching and learning in the interactionprocess: "Keys" for developing skills in piano lessons through fourhand improvisations. J. Pedagogy 5, 24-47. doi: 10.2478/jped-2014-0002

Lehmann, A., and Schönwiesner, M. (2014). Selective attention modulates human auditory brainstem responses: relative contributions of frequency and spatial cues. PLoS ONE 9:e85442. doi: 10.1371/journal.pone.0085442

Lenay, C., and Stewart, J. (2012). Minimalist approach to perceptual interactions. Front. Hum. Neurosci. 6:98. doi: 10.3389/fnhum.2012.00098

Lutz, A., Lachaux, J. P., Martinerie, J., and Varela, F. J. (2002). Guiding the study of brain dynamics by using first-person data: synchrony patterns correlate with ongoing conscious states during a simple visual task. Proc. Natl. Acad. Sci. U.S.A. 99, 1586-1591. doi: 10.1073/pnas.032658199
Makeig, S., Gramann, K., Jung, T. P., Sejnowski, T. J., and Poizner, H. (2009). Linking brain, mind and behavior. Int. J. Psychophysiol. 73, 95-100. doi: 10.1016/j.ijpsycho.2008.11.008

Manson, J. H., Bryant, G. A., Gervais, M. M., and Kline, M. A. (2013). Convergence of speech rate in conversation predicts cooperation. Evol. Hum. Behav. 34, 419-426. doi: 10.1016/j.evolhumbehav. 2013.08.001

Marmelat, V., Torre, K., Beek, P. J., and Daffertshofer, A. (2014). Persistent fluctuations in stride intervals under fractal auditory stimulation. PLoS ONE 9:e91949. doi: 10.1371/journal.pone. 0091949

Marsh, K. L., Johnston, L., Richardson, M. J., and Schmidt, R. C. (2009). Toward a radically embodied, embedded social psychology. Eur. J. Soc. Psychol. 39, 1217-1225. doi: 10.1002/ejsp.666

Müller, V., Sänger, J., and Lindenberger, U. (2013). Intra- and inter-brain synchronization during musical improvisation on the guitar. PLOS ONE 8:e73852. doi: 10.1371/journal.pone.0073852

Nadel, J., Carchon, I., Kervella, C., Marcelli, D., and Réserbat-Plantey, D. (1999). Expectancies for social contingency in 2-month-olds. Dev. Sci. 2, 164-173. doi: 10.1111/1467-7687.00065

Novembre, G., and Keller, P. E. (2014). A conceptual review on action-perception coupling in the musicians' brain: what is it good for? Front. Hum. Neurosci. 8:603. doi: 10.3389/fnhum.2014.00603

Noy, L., Dekel, E., and Alon, U. (2011). The mirror game as a paradigm for studying the dynamics of two people improvising motion together. Proc. Natl. Acad. Sci. U.S.A. 108, 20947-20952. doi: 10.1073/pnas.1108155108

Nozaradan, S., Peretz, I., Missal, M., and Mouraux, A. (2011). Tagging the neuronal entrainment to beat and meter. J. Neurosci. 31, 10234-10240. doi: 10.1523/JNEUROSCI.0411-11.2011

Nozaradan, S., Peretz, I., and Mouraux, A. (2012). Selective neuronal entrainment to the beat and meter embedded in a musical rhythm. J. Neurosci. 32, 17572-17581. doi: 10.1523/JNEUROSCI.320312.2012

Nozaradan, S., Zerouali, Y., Peretz, I., and Mouraux, A. (2013). Capturing with EEG the neural entrainment and coupling underlying sensorimotor synchronization to the beat. Cereb. Cortex. doi: 10.1093/cercor/bht261. [Epub ahead of print].

Okubo, A. (1986). Dynamical aspects of animal grouping: swarms, schools, flocks, and herds. $A d v$. Biophys. 22, 1-94. doi: 10.1016/0065-227X(86) 90003-1

Paxton, A., and Dale, R. (2013). Frame-differencing methods for measuring bodily synchrony in conversation. Behav. Res. Methods 45, 329-343. doi: 10.3758/s13428-012-0249-2

Petitmengin, C., and Lachaux, J. P. (2013). Microcognitive science: bridging experiential and neuronal microdynamics. Front. Hum. Neurosci. 7:617. doi: 10.3389/fnhum.2013.00617

Phillips-Silver, J., Aktipis, C. A., and Bryant, G. A. (2010). The ecology of entrainment: foundations of coordinated rhythmic movement. Music Percept. 28:3. doi: 10.1525/mp.2010.28.1.3

Rankin, S. K., Edward, W., and Fink, P. W. (2009). Fractal tempo fluctuation and pulse prediction. Music Percept. 26, 401-413. doi: 10.1525/mp.2009. 26.5.401 
Ross, J. M., and Balasubramaniam, R. (2014). Physical and neural entrainment to rhythm: human sensorimotor coordination across tasks and effector systems. Front. Hum. Neurosci. 8:576. doi: 10.3389/fnhum.2014.00576

Sacheli, L. M., Tidoni, E., Pavone, E. F., Aglioti, S. M., and Candidi, M. (2013). Kinematics fingerprints of leader and follower role-taking during cooperative joint actions. Exp. Brain Res. 226, 473-486. doi: 10.1007/s00221-013-3459-7

Sänger, J., Müller, V., and Lindenberger, U. (2012). Intra- and interbrain synchronization and network properties when playing guitar in duets. Front. Hum. Neurosci. 6:312. doi: 10.3389/fnhum.2012.00312

Sänger, J., Müller, V., and Lindenberger, U. (2013). Directionality in hyperbrain networks discriminates between leaders and followers in guitar duets. Front. Hum. Neurosci. 7:234. doi: 10.3389/fnhum.2013.00234

Schilbach, L., Timmermans, B., Reddy, V., Costall, A., Bente, G., Schlicht, T., et al. (2013). Toward a second-person neuroscience. Behav. Brain Sci. 36, 393-414. doi: 10.1017/S0140525X12000660

Schmidt, R. C., Christianson, N., Carello, C., and Baron, R. (1994). Effects of social and physical variables on between-person visual coordination. Ecol. Psychol. 6, 159-183. doi: 10.1207/s15326969 eco0603_1

Silberstein, M., and Chemero, A. (2012). Complexity and extended phenomenological-cognitive systems. Topics Cogn. Sci. 4, 35-50. doi: 10.1111/j. 1756-8765.2011.01168.x
Stopczynski, A., Stahlhut, C., Petersen, M. K., Larsen, J. E., Jensen, C. F., Ivanova, M. G., et al. (2014). Smartphones as pocketable labs: visions for mobile brain imaging and neurofeedback. Int. J. Psychophysiol. 91, 54-66. doi: 10.1016/j.ijpsycho.2013.08.007

Strogatz, S. (2003). Sync: The Emerging Science of Spontaneous Order. New York, NY: Theia (Hyperion).

Sze, J. A., Gyurak, A., Yuan, J. W., and Levenson, R. W. (2010). Coherence between emotional experience and physiology: does body awareness training have an impact? Emotion 10, 803-814. doi: 10.1037/a0020146

Toiviainen, P., Luck, G., and Thompson, M. R. (2010). Embodied meter: hierarchical eigenmodes in music-induced movement. Music Percept. 28, 59-70. doi: 10.1525/mp.2010.28.1.59

Van Orden, G. C., Holden, J. G., and Turvey, M. T. (2003). Self-organization of cognitive performance. J. Exp. Psychol. Gen. 132, 331-350. doi: 10.1037/0096-3445.132.3.331

Varela, F. J. (1979). Principles of Biological Autonomy. New York, NY: North Holland.

Varela, F. J., Rosch, E., and Thompson, E. (1993). The Embodied Mind: Cognitive Science and Human Experience. Cambridge, MA: MIT press.

Varlet, M., Marin, L., Capdevielle, D., Del-Monte, J., Schmidt, R. C., Salesse, R. N., et al. (2014). Difficulty leading interpersonal coordination: towards an embodied signature of social anxiety disorder. Front. Behav. Neurosci. 8:29. doi: 10.3389/fnbeh.2014.00029
Vickhoff, B., Malmgren, H., Aström, R., Nyberg, G., Ekström, S.-R., Engwall, M., et al. (2013) Music structure determines heart rate variability of singers. Front. Psychol. 4:334. doi: 10.3389/fpsyg.2013.00334

Vogeley, K., and Roepstorff, A. (2009). Contextualising culture and social cognition. Trends Cogn. Sci. 13, 511-516. doi: 10.1016/j.tics. 2009.09.006

Conflict of Interest Statement: The authors declare that the research was conducted in the absence of any commercial or financial relationships that could be construed as a potential conflict of interest.

Received: 23 September 2014; accepted: 25 November 2014; published online: 16 December 2014.

Citation: Dumas G, Laroche J and Lehmann A (2014)

Your body, my body, our coupling moves our bodies. Front. Hum. Neurosci. 8:1004. doi: 10.3389/fnhum. 2014.01004

This article was submitted to the journal Frontiers in Human Neuroscience.

Copyright (c) 2014 Dumas, Laroche and Lehmann. This is an open-access article distributed under the terms of the Creative Commons Attribution License (CC BY). The use, distribution or reproduction in other forums is permitted, provided the original author(s) or licensor are credited and that the original publication in this journal is cited, in accordance with accepted academic practice. No use, distribution or reproduction is permitted which does not comply with these terms. 